\title{
FABRICATION AND EVALUATION OF A MACHINE FOR SEPARATING FIBER FLAX
}

\author{
A. M. DRESS
}

\section{ABSTRACT}

Flax stalks usually considered a waste product which may be utilized by separation into marketable fiber and shive. The fiber can be used for applications such as composites and paper. Separation of traditional long line fiber from fiber flax stalks is a rigorous and expensive process that requires the stalk to be biologically degraded (retted) befor processing. A local machine for removing flax fiber from chopped seed flax straw has been manufactured at a private workshop in kafr El-sheikh Governorate during summer season of 2015. The manufactured machine consists of three main devices namely: feeding and breaking device, scutching and hackling device and cleaning device. The manufactured machine has been evaluated under three straw moisture contents of 10.2, 13.2and $15 \%$, three deram schell speeds of 500, 650 and 800 rpm and five feeding roller speeds of 1, 1.5, 2, 2.5and $3 \mathrm{~m} / \mathrm{s}$. The Separation efficiency, fiber longth and fineness, machine Productivity, consumed Energy, and quality of fiber were studied. The obtained results can be summarized as follows: The maximum separation efficiency of flax fiber (82.13\%) and fiber fineness (191.6 mm/mg) was obtained at straw moisture content Of $10.2 \%$, feeding roller speed of $1 \mathrm{~m} / \mathrm{sec}$ and derma schell speed of 800 r.p.m. The fiber Length $(92.8 \mathrm{~cm})$ was obtained at straw moisture content of $10.2 \%$, feeding roller speed of $1 \mathrm{~m} / \mathrm{sec}$ and derma schell speed of 500 r.p.m. The lowest value of energy consumption was $(1 \mathrm{kw})$ recorded at straw moisture content of $10.2 \%$, feeding roller speed of $1 \mathrm{~m} / \mathrm{s}$ and dearm schell speed of 500 r.p.m. It is recommended for the operators of the manufactured separation machine to operate it at straw moisture content of $10.2 \%$, feeding roller speed of $1 \mathrm{~m} / \mathrm{s}$ and derma schell speed of 800 r.p.m to obtain the optimum performance.

Keywords: flax, separating fibers, design, cleaning, consumed energy, machine evaluation.

* Assoc. Prof., Ag. Eng. Dept., Fac. of Agric., AL-Azhar University- Assuit. 


\section{INTRODUCTION}

$\mathrm{F}$ lax considers the most important economic oil and fiber crops in all over the world as well as in Egypt. Flax (Limum usitatissimum

L)fibers for cloth originated about 10,000 years ago. Ancient Egyptians placed scenes of flax cultivation on the walls of tombs, and bobies were mummified in flax shrouds (Oelke et al., 1987).The flax stalk consists of fiber bundles located between the epidermis or bark surface and an inner wood core (shive). The fiber bundles in flax stalks are usually separated into individual fibers before use. Two general types of flax are grown- fiber flax and seed flax. Fiber is extracted from fiber flax stalks and divided into two classes. The short, damaged fiber called tow is sometimes known as cottonized flax and is used in lower quality fabrics. Tow is also blended with other products such as cotton to make fabric. The fiber separating processes in many steps such as retting, drying, breeking and separating so, they need a hard effort and high cost. Retting is the process of rotting away the inner stalk, leaving the outer fibres intact

Mollog (2000) reported that fiber percentage in the flax straw increases from flowering to maturity from around 17 to $25 \%$, it remains constant at around $16 \%$ in linseed.

Eichhom (2001) found that the mechanical properties of flax: density 1.5 $\mathrm{g} / \mathrm{cm}^{3}$, break $2.7-3.2 \%$, tensile strength $345-1035 \mathrm{Mpa}$, young's modulus 27.6 Gpa. While these two natural fibers are similar, the properties of the plant as well as the mandatory processing to obtain fibers vary greatly. Flax stalks contain approximately $30 \%$ fiber and $70 \%$ trash.

Mohanty et al., (2001) remembered that the flax density was $1.5 \mathrm{~g} / \mathrm{cm}^{3}$, tensile strength was 345-1100 (Mpa) young's modulus $27.6(\mathrm{Gpa})$ and elongation at Break was $2.2-3.2 \%$.

Fouda et al (2011) found that the separation efficiency of flax fibers $74 \%$ with vibration movement at sieve speed of $2.8 \mathrm{~m} / \mathrm{s}$, feeding rate of $100 \mathrm{~kg} / \mathrm{h}$ and moisture content of $7.75 \%$. The fibers length of $89.5 \mathrm{~cm}$ were obtained at sieve speed of $1.6 \mathrm{~m} / \mathrm{s}$, feeding rate of $100 \mathrm{~kg} / \mathrm{h}$ and moisture content of $7.75 \%$. The best degree of fiber fineness $(182.6 \mathrm{~mm} / \mathrm{mg})$ was at sieve speed of $2.8 \mathrm{~m} / \mathrm{s}$, feeding rate of $100 \mathrm{~kg} / \mathrm{hr}$ and moisture content of $7.75 \%$. 
Anthony (2002) run three studies to determine the cleaning effectiveness of gin machinery in separating flax fiber from chopped seed flax straw. His three studies used various combinations of cylinder cleaners and lint cleaners and flax raw material chopped to about $5.1 \mathrm{~cm}$ in length, retrieval of pure fiber (corrected for shive content) ranged from a low of $7.1 \%$ to a high of $12.8 \%$.

Anthony (2005) evaluated the potential of several machines to remove flax fiber from chopped seed flax straw. Then, a new machine that incorporated the principles of several machines was built and tested. The initial version of the machine did not yield the desired $80 \%$ fiber purity, so more saw cylinders were added. The most effective version produced $13.8 \%$ yield out of a possible $20 \%$ fibber with a purity of $81.4 \%$. The yield can be improved with additional modifications to the machine.

Ismail (2009) indicated that the degree of fibers fineness decreased by the increase in straw moisture content., the highest value of fiber fineness of $129.74 \mathrm{~mm} / \mathrm{mg}$ was obtained at straw moisture content of $8.42 \%$, while the lowest value of fiber fineness of $126.63 \mathrm{~mm} . / \mathrm{mg}$ was obtained at straw moisture content of $12.6 \%$. The Egyptian farmers do not have any small-scale machines to help them for separating flax fibers. Raising the income of the farmer, achieved by using a simple mechanical system using for separating flax fibers, which, reduces all losses and save transporting costs. Consequently, reduces the problems face Egyptian farmers farmer sells their crops after harvesting with low prices, and also affected the main physical and mechanical properties of flax fibers were. The main objective of the present is to manufacture a local machine for separating flax fibers and evaluate the performance of this machine under different operating conditions.

\section{MATERIALS AND METHODS}

A machine for flax fibers separation was fabricated at a private rural workshop in kafr El-sheikh Governorate during the summer season of 2015. The unit consists of the following main parts:

a- Feeding and breaking mechanism.

b- Scutching and hackling mechanism.

c- Cleaning mechanism.

d- The machine frame on which al the components assembled 
e- Electric power motor and transmission.

The machine frame made of angle iron $(4 \times 4 \mathrm{~cm})$ with dimensions of $153 \mathrm{~cm}$ length, $60 \mathrm{~cm}$ width and $85 \mathrm{~cm}$ height as shown in fig 1.



1- frame

2- decentralized cam

3- electric motor
4- cleaning device

5- $\quad$ feeding and breaking device

6- $\quad$ scutching and hackling device

Figure1. Side view of the fabricated machine for separating flax fibers .

The feeding and breaking device consists of two cylinder of grooved surface with $60 \mathrm{~cm}$ length; $10 \mathrm{~cm}$ diameter overlaped $1 \mathrm{~cm}$. The function of feeding and breaking mechanism feed is to and crack the inner wood of the flax straw. The machine is powered by $2 \mathrm{hp}$ electric motor. A gearbox was used for power transmission and speed reduction. as shown in fig 2 .

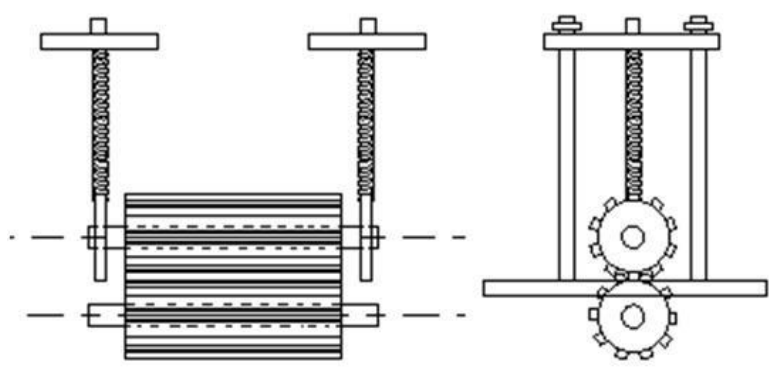

Figure2. Elevation and side view of the feeding and breaking device in machine for showing the overlap of the cylinder surface tooth. 
The scutching and hackling device consists of a vicious surface cylinder with $60 \mathrm{~cm}$ diameter. The mechanism turned at 500- 850 r.p.m rotational speed and equipped with 4 iron poles shaped as a comb teeth, This pullets were fixed on the outer surface of the cylinder assembled parallel to the main axis of the cylinder. The main function of this device is to separate the flax fibers from the inner bark of the flax stalks. It was powered by the electric motor and a set of pulleys in addition to conveyor belts as shown in fig. 3.

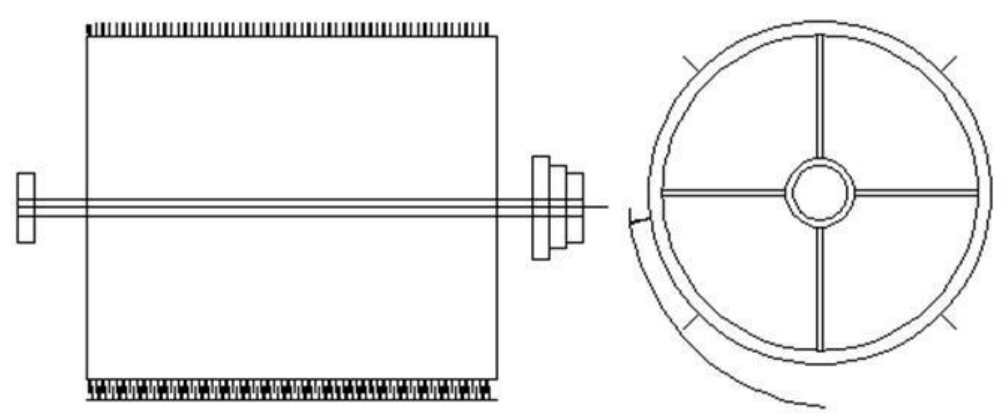

Figure3. Side view of the scutching and hackling device .

The cleaning device consists of a flat surface steel sheet with $80 \times 60 \mathrm{~cm}$ dimensions that assembled with inclination of about 25 degree and provided with a series of rectangular openings its dimensions of $10 \times 0.5$ $\mathrm{cm}$. The mechanism moves reciprocating that generat vibrating by decentralized cam. This device converts the rotational motion into reciprocating movement to clean the linen fibers from the wood pieces and internal bark before discharge from the machine as shown in fig. 4.

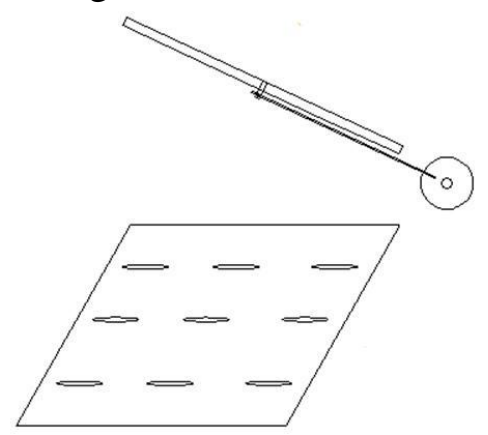

Figure4. The cleaning device in machine for separating flax fibers fabricated. 
Field experiments were conducted to evaluate the performance of the manufactured separating machine under the following parameters:-

1- Three straw moisture contents (10.2, 13.2 and 15\%).

2- Fives feeding roller speeds $(1,1.5,2,2.5$ and $3 \mathrm{~m} / \mathrm{s})$.

3- Three derma schell speeds $(500,650$, and 800 r.p.m).

After harvesting and separating the seeds from flax plants the stalks were connected and sent for retting stalk. The retting process takes about 7-15 days, and then plants were dried in the yard for a few days. After that breaking process was undertaken in order to crush by passing stalks into breaking machine through fluted rollers. Cutting stalks into small pieces of bark is called shaves. Then the broken stalks transferred [ $\mathrm{n}$ to the cleaning machine to separate the fibers from the shaves with rotating sieve and finally releasing the flax fibers from stalks. Some physical properties of flax are shown in table 1.

Table (1): Some physical properties of straw flax.

\begin{tabular}{|l|l|}
\hline Physical properties & Main value \\
\hline Plant height, mm & 1140 \\
\hline Technical length, mm & 989 \\
\hline Stalk diameter, mm & 3.45 \\
\hline Straw yield, ton/fed & 3.28 \\
\hline Length of root zone, $\mathrm{mm}$ & $120-150$ \\
\hline Fibres percent \% & $20 \%$ \\
\hline Woody- shaves \% & $80 \%$ \\
\hline
\end{tabular}

\section{Measurements:}

\section{Straw moisture content:}

Straw moisture content was determined after retting times at different three stages of drying by taking a five straw samples randomly after 10,15 and 20 days from retting these samples were dried in the oven at $70 \dot{\mathrm{C}}$ for 24 hours. The straw moisture content was calculated according to (Fouda, 2011) using the following equation.

$$
M=\frac{\mathrm{M}_{\mathrm{ws}}-\mathrm{M}_{\mathrm{ds}}}{\mathrm{M}_{\mathrm{ws}}} \times 100
$$

\section{Where:}

$\mathrm{M}=$ Straw moisture content, $\%$

$\mathrm{M}_{\mathrm{WS}}=$ Wet straw weight, $\mathrm{g}$.

$\mathrm{M}_{\mathrm{dS}}=$ Dry straw weight, $\mathrm{g}$. 


\section{Separating efficiency:}

Separating efficiency was estimated by using the following equation.

Where:

$$
S_{p}=\frac{\mathrm{W}_{\mathrm{B}}-\mathrm{W}_{\mathrm{A}}}{\mathrm{W}_{\mathrm{B}}} \times 100
$$

$$
\begin{aligned}
& \mathrm{S}_{\mathrm{P}}=\text { separating efficiency, } \% \\
& \mathrm{~W}_{\mathrm{B}}=\text { Total weight of wood pieces, } \mathrm{kg} \\
& \mathrm{W}_{\mathrm{A}}=\text { Total weight of wood pieces with fibres, } \mathrm{kg}
\end{aligned}
$$

\section{Machine Productivity:}

Time of separating flax fibres process was measured by means of a stop watch. The capacity of the machine was calculated as follows:

$$
\mathrm{P}_{\mathrm{m}}=\frac{\mathrm{W}}{\mathrm{T}}
$$

Where

$\mathrm{P}_{\mathrm{m}} \quad$ : Machine Productivity, $\mathbf{k g ~ h} \mathrm{h}^{-1}$.

W : Mass of sample, $\mathrm{kg}$.

$\mathrm{T}$ : Separating time ,h.

\section{Consumed energy $(C E)$}

The required electric power was measured for cleaning and grading process. The required electric power was calculated to ( Lockwood and Dunstan, 1971) by using the following equation.

$$
\begin{aligned}
R P & =\sqrt{ } 3 \times \mathrm{V} \times \mathrm{I} \times \eta \times \cos \theta \\
\text { Useful power }= & \text { load }- \text { no load }) .
\end{aligned}
$$

Where

RP : The required power, W.

V : $\quad$ Potential difference, Voltage ( 3 phase $=380$ voltage).

I : Line current strength, Amperes.

$\cos \theta \quad: \quad$ Power factor, equal 0.84 .

$\eta \quad$ : Mechanical efficiency assumed (95\%).

A digital clamp meter and Voltmeter were used for measuring current intensity and voltage respectively. 


\section{Fiber fineness:}

Fiber fineness in metrical number, was determined according to (Radwan and Momtaz, 1966) using the following equation.

$$
N_{m}=\frac{\mathrm{N}-L}{G} \times 100
$$

Where:

$\mathrm{N}_{\mathrm{m}}=$ metrical number $(\mathrm{mm} / \mathrm{mg})$

$\mathrm{N}=$ No. fibres (20 fibres each $10 \mathrm{~cm}$ ).

$\mathrm{L}=$ length of fibres in $\mathrm{mm}, 2000$.

$\mathrm{G}=$ weight of fibres, $\mathrm{mg}$.

\section{6- Long fiber percentage:}

Long fibre length was measured using a scale meter (model).And determined (very long. Medium, short and very short) of flax fibres.

\section{Long fibre strength (tension force):}

Long fiber strength was measured by using prissily implement according to( Radwan and Momtaz ,1966) using the following formula:

$$
F_{s}=\frac{\mathrm{N} \times L \times C_{f}}{G}
$$

Where:

$\mathrm{F}_{\mathrm{s}}=$ Fibbers strength, $\mathrm{mm}$. N/mg.

$\mathrm{N}=$ Number of 20 fibres tested (fibers' each $10 \mathrm{~cm}$ ).

$\mathrm{L}=$ length of tested fibers, $\mathrm{mm}$.

$\mathrm{G}=$ weight of tested fibres, $\mathrm{mg}$.

$\mathrm{C}_{\mathrm{f}}=$ Mean of the tensile force for breaking an individual fibers, $\mathrm{N}$.

\section{RESULTS AND DISCUSSIONS}

\section{1- Separation efficiency:}

The separation efficiency is an important parameter to evaluate the performance of separating machine. Table 2 and fig 5 show the efficiency of the manufactured separating machine as affected by straw moisture content, feeding roller speed and derma Schell speed. Data indicated that 
the increment in straw moisture content from 10.2 to $15 \%$. decreases the separation efficiency of the manufactured machine from 71.36 to 42.23 $\%$.

Table (2) Mean values of Separation efficiency, machine Productivity for fiber flax separation at different moisture content, feeding roller speed and derma Schell Speed.

\begin{tabular}{|c|c|c|c|c|c|c|c|c|}
\hline \multirow{3}{*}{$\begin{array}{l}\text { M. C } \\
, \%\end{array}$} & \multirow{3}{*}{\multicolumn{2}{|c|}{$\begin{array}{l}\text { feeding roller } \\
\text { Speed }, \mathrm{m} / \mathrm{sec}\end{array}$}} & Separ & ion effic & nсу $\%$ & mach & roductivity & $\mathrm{g} / \mathrm{hr}$ \\
\hline & & & \multicolumn{6}{|c|}{ Derma Schell Speed, r.p. m } \\
\hline & & & 500 & 650 & 800 & 500 & 650 & 800 \\
\hline \multirow{5}{*}{10.2} & \multicolumn{2}{|c|}{1} & 74.2 & 78.7 & 82.13 & 38.2 & 37.5 & 36.2 \\
\hline & \multicolumn{2}{|c|}{1.5} & 73 & 75.1 & 77.4 & 43.51 & 42.7 & 38.6 \\
\hline & \multicolumn{2}{|c|}{2} & 71.8 & 73.6 & 75.1 & 46.2 & 45.5 & 43.4 \\
\hline & \multicolumn{2}{|c|}{2.5} & 70 & 71.2 & 73 & 49 & 48 & 45.6 \\
\hline & \multicolumn{2}{|c|}{3} & 67.8 & 69.3 & 70.8 & 52.8 & 52 & 48.8 \\
\hline \multirow{5}{*}{13.2} & \multicolumn{2}{|c|}{1} & 65.3 & 68.7 & 70.15 & 47.95 & 46.06 & 44.3 \\
\hline & \multicolumn{2}{|c|}{1.5} & 64 & 66.2 & 65.1 & 53.76 & 52.1 & 47.4 \\
\hline & \multicolumn{2}{|c|}{2} & 63.1 & 65 & 64.6 & 57.2 & 55 & 53.6 \\
\hline & \multicolumn{2}{|c|}{2.5} & 60.4 & 61.8 & 63.1 & 60.8 & 57.3 & 56.12 \\
\hline & \multicolumn{2}{|c|}{3} & 57.5 & 59.4 & 61.2 & 64.66 & 63.7 & 60.5 \\
\hline & \multicolumn{2}{|c|}{1} & 45.8 & 49.2 & 54.6 & 52.69 & 50.9 & 49 \\
\hline & \multicolumn{2}{|c|}{1.5} & 44.1 & 45.7 & 53 & 60.7 & 57.2 & 56.1 \\
\hline 15 & \multicolumn{2}{|c|}{2} & 42 & 44.1 & 51 & 65 & 61.6 & 58.9 \\
\hline & \multicolumn{2}{|c|}{2.5} & 40 & 42.8 & 49.7 & 68.3 & 64.2 & 63 \\
\hline & \multicolumn{2}{|c|}{3} & 39.25 & 40.3 & 45.8 & 72.1 & 67.35 & 65.12 \\
\hline \multicolumn{3}{|c|}{ Mean values of derma Schell Speed } & 58.55 & 60.74 & 63.77 & 55.52 & 53.40 & 51.10 \\
\hline \multicolumn{3}{|c|}{ Mean values of straw } & 71.36 & 73.58 & 75.68 & 45.94 & 45.14 & 42.52 \\
\hline \multirow{2}{*}{\multicolumn{2}{|c|}{$\begin{array}{l}\text { Mean values of Straw } \\
\text { moisture content }\end{array}$}} & 13.2 & 62.06 & 64.22 & 64.83 & 56.87 & 54.83 & 52.38 \\
\hline & & 15 & 42.23 & 44.42 & $\begin{array}{l}50.82 \\
\end{array}$ & 63.75 & 60.25 & 58.42 \\
\hline \multirow{5}{*}{\multicolumn{2}{|c|}{$\begin{array}{l}\text { Mean values of feeding } \\
\text { roller Speed }\end{array}$}} & 1 & 61.76 & 65.53 & 68.96 & 46.28 & 44.82 & 43.16 \\
\hline & & 1.5 & 60.36 & 62.33 & 65.16 & 52.65 & 50.66 & 47.36 \\
\hline & & 2 & 58.96 & 60.9 & 63.63 & 56.13 & 54.03 & 51.96 \\
\hline & & 2.5 & 56.8 & 58.6 & 61.93 & 59.36 & 56.5 & 54.9 \\
\hline & & 3 & 54.85 & 56.33 & 59.26 & 63.18 & 61.016 & 58.14 \\
\hline
\end{tabular}

The maximum separation efficiency was obtained with the straw moisture content of $10.2 \%$ for all the feeding roller and derma schell speeds. The data also observed that increasing the feeding roller speed tends to decrease the separation efficiency. The feeding roller speed of $1 \mathrm{~m} / \mathrm{s}$ gave the maximum average value of separation efficiency of $75.68 \%$ at straw moisture content of $10.2 \%$ and derma schell speed of 650 r.p.m. On the other hand, the obtained average values of separation efficiency were 74.2, 78.7 and $82.2 \%$ at derma Schell speeds of 500, 650 and 800 r.p.m with straw moisture content of $10.2 \%$ and feeding roller speed of $1 \mathrm{~m} / \mathrm{s}$. 
Generally, it is clear that the straw moister content of $10.2 \%$, feeding roller speed of $1 \mathrm{~m} / \mathrm{s}$ and derma schell speed of 800 r.p.m gave the maximum separation efficiency of $82.1 \%$ however, the minimum separation efficiency of $39.3 \%$ was recorded with the straw moisture content of $15.0 \%$, feeding roller speed of $3 \mathrm{~m} / \mathrm{s}$ and derma schell speed of 500 r.p.m .

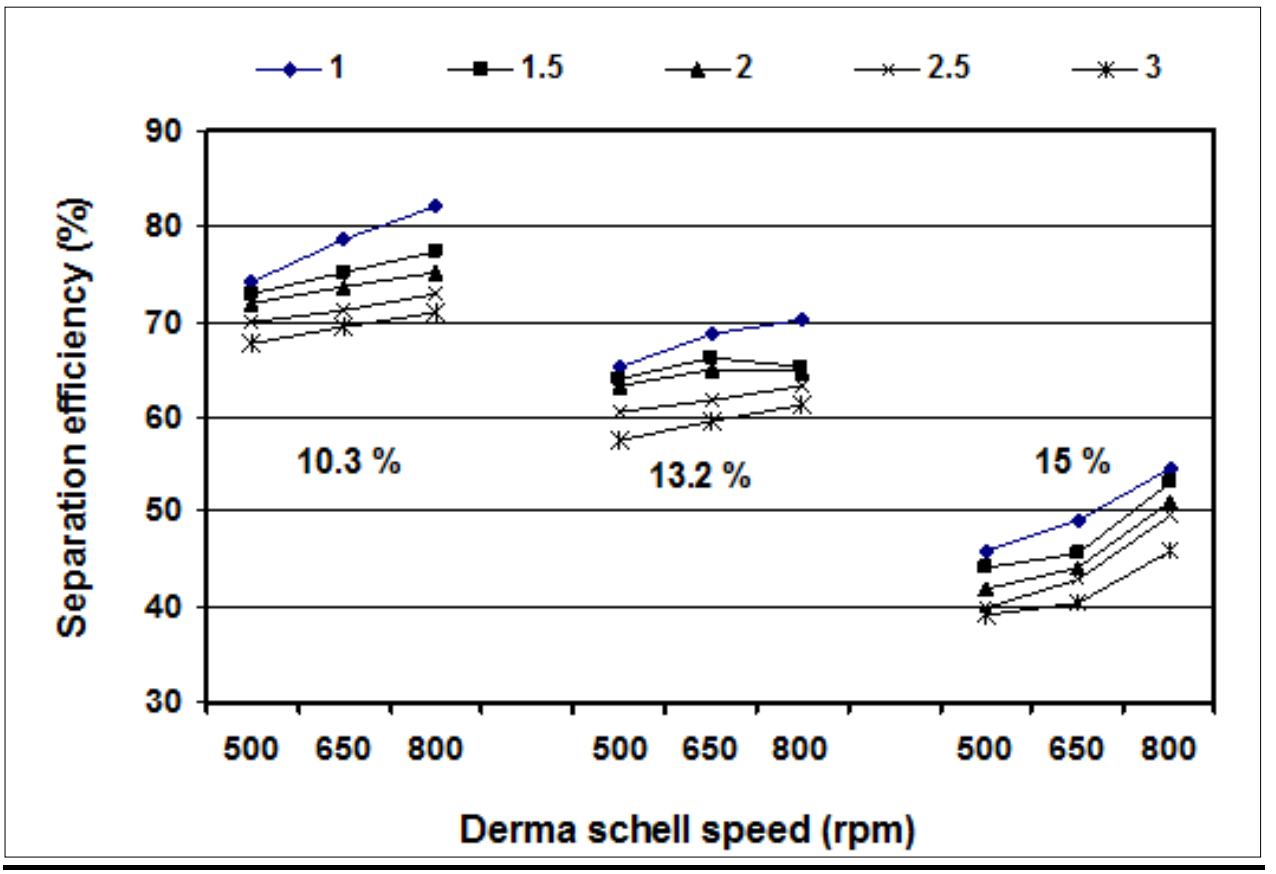

Fig.5: Effect of straw moisture content, feeding roller speed and derma schell speed on separation efficiency.

\section{2- Machine Productivity:}

The machine Productivity is an important parameter to evaluate the performance of separating machine. Table 2 and fig 6 show the Productivity of the manufactured separating machine as affected by straw moisture content, feeding roller speed and derma Schell speed. Data illustrated that the increment in straw moisture content from 10.2 to $15 \%$. tend to increase the machine Productivity from 45.94 to $63.75 \mathrm{~kg} / \mathrm{h}$. The maximum values machine Productivity was obtained with the straw moisture content of $15 \%$ for all the feeding roller and derma schell speeds. The data also revealed that the machine productivity increased 
when the feeding roller speed increased for all the straw moisture contents and derma schell speeds. The feeding roller speed of $3 \mathrm{~m} / \mathrm{s}$ gave the maximum average value of machine Productivity of $72.1 \mathrm{~kg} / \mathrm{h}$ at straw moisture content of $15 \%$ and derma schell speed of 500 r.p.m. On the other hand, the obtained average values of machine Productivity were $72.1,67.35$ and $65.12 \mathrm{~kg} / \mathrm{h}$ at derma schell speeds of 500, 650 and 800 r.p.m respectively, with straw moisture content of $15 \%$ and feeding roller speed of $3 \mathrm{~m} / \mathrm{s}$. Generally, it is clear that the straw moister content of 15 $\%$, feeding roller speed of $3 \mathrm{~m} / \mathrm{s}$ and derma Schell speed of 500 r.p.m gave the maximum machine Productivity of $72.1 \mathrm{~kg} / \mathrm{h}$ but, the minimum Productive machine of $36.2 \mathrm{~kg} / \mathrm{h}$ was recorded with the straw moisture content of $10.2 \%$, feeding roller speed of $1 \mathrm{~m} / \mathrm{s}$ and derma Schell speed of 500 r.p.m. These results may be due to the increasing derma Schell speed leading to increase the losses in flax fiber.

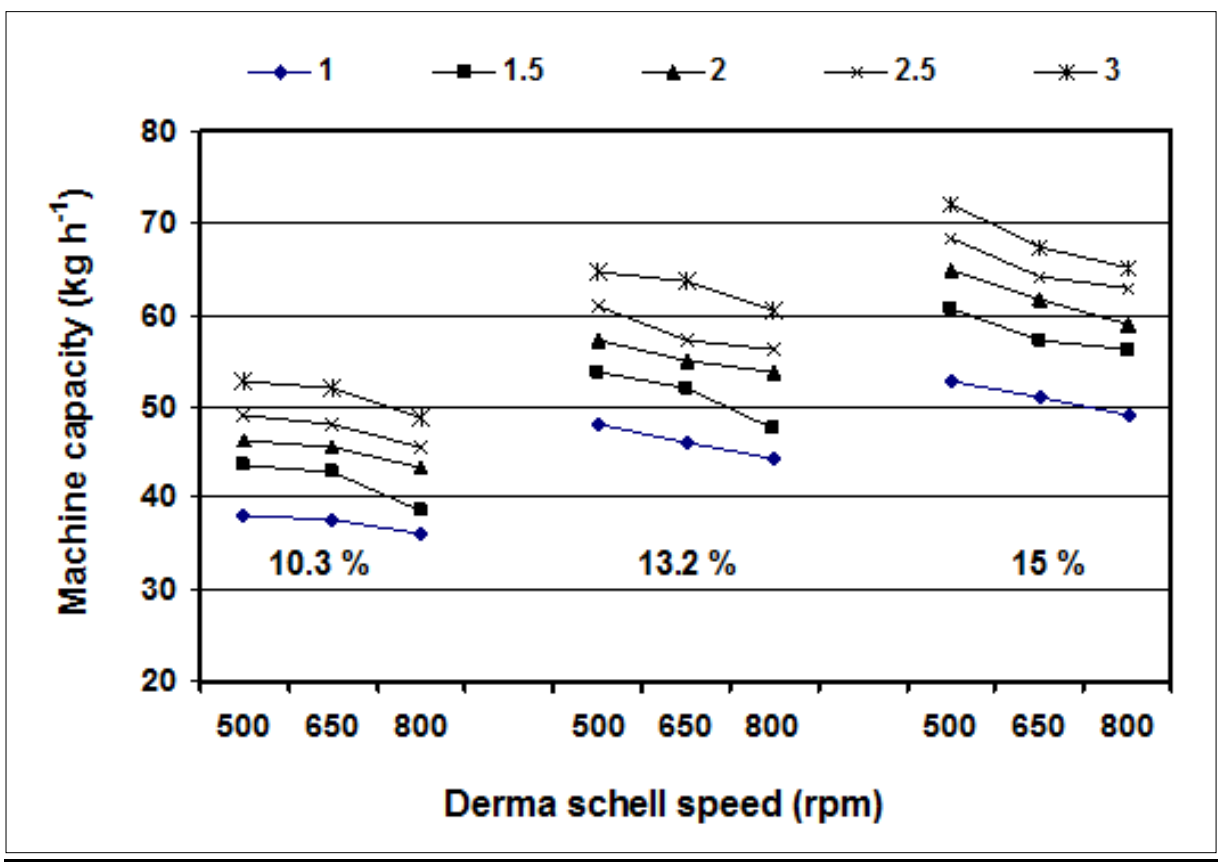

Fig.6: Effect of straw moisture content, feeding roller speed and derma schell speed on machine Productivity.

\section{3 - Consumed Energy:}

There was a significant effect of straw moisture content, feeding roller speed and derma schell speed on the Consumed energy as shown in Table 
3 and fig 7 It is evident that, the Consumed energy decreased by decreasing the straw moisture content for all the feeding roller and derma schell speeds. The straw moisture content of $10.2 \%$ consumed the minimum value of energy of $1 \mathrm{kw}$ at feeding roller speed of $1 \mathrm{~m} / \mathrm{s}$ and derma Schell speed of 500 r.p.m. These results may be due to increasing derma schell speed and feeding roller speed led to increase consumed energy in unit time through the material of flax stalk. The feeding roller speeds of 1, 1.5, 2, 2.5 and $3 \mathrm{~m} / \mathrm{s}$ gave consumed energy of 1, 1.2, 1.3, 1.4 and $1.6 \mathrm{kw}$, respectively, at straw moisture content of $10.2 \%$ and derma schell speed of 500 r.p.m.

Table (3) Mean values Consumed energy, fineness fiber, $\mathrm{mm} / \mathrm{mg}$ for separation fiber flexes at different moisture content, feeding roller speed and derma Schell Speeds.

\begin{tabular}{|c|c|c|c|c|c|c|c|c|}
\hline \multirow{3}{*}{$\begin{array}{l}\text { M. C } \\
, \%\end{array}$} & \multirow{3}{*}{\multicolumn{2}{|c|}{$\begin{array}{l}\text { feeding roller } \\
\text { Speed }, \mathrm{m} / \mathrm{sec}\end{array}$}} & $\mathrm{Co}$ & med el & , kw & & ss fiber , & \\
\hline & & & \multicolumn{6}{|c|}{ Derma Schell Speed, r.p. m } \\
\hline & & & 500 & 650 & 800 & 500 & 650 & 800 \\
\hline \multirow{5}{*}{10.2} & \multicolumn{2}{|c|}{$\overline{1}$} & 1 & 1.1 & 1.3 & 158.2 & 175.3 & 191.6 \\
\hline & \multicolumn{2}{|c|}{1.5} & 1.2 & 1.3 & 1.5 & 155.8 & 172.8 & 188.3 \\
\hline & \multicolumn{2}{|c|}{2} & 1.3 & 1.4 & 1.7 & 153.3 & 170.1 & 185.6 \\
\hline & \multicolumn{2}{|c|}{2.5} & 1.4 & 1.6 & 1.9 & 150.4 & 169 & 182.7 \\
\hline & \multicolumn{2}{|c|}{3} & 1.6 & 1.8 & 2 & 147.1 & 166.8 & 180 \\
\hline \multirow{5}{*}{13.2} & \multicolumn{2}{|c|}{1} & 1.19 & 1.28 & 1.46 & 155 & 169.3 & 180.9 \\
\hline & \multicolumn{2}{|c|}{1.5} & 1.38 & 1.4 & 1.65 & $\begin{array}{l}153.7 \\
\end{array}$ & 166.2 & 177.6 \\
\hline & \multicolumn{2}{|c|}{2} & 1.45 & 1.6 & 1.72 & 152.1 & 164 & 175 \\
\hline & \multicolumn{2}{|c|}{2.5} & 1.62 & 1.78 & 1.85 & 150 & 161.5 & 171.8 \\
\hline & \multicolumn{2}{|c|}{3} & 1.85 & 1.95 & 2.05 & 145.1 & 157.2 & 167.2 \\
\hline & \multicolumn{2}{|c|}{1} & 1.37 & 1.5 & 1.65 & 148.2 & 160 & 169.3 \\
\hline & \multicolumn{2}{|c|}{1.5} & 1.5 & 1.75 & 1.85 & 145.6 & 157.3 & 166.1 \\
\hline 15 & \multicolumn{2}{|c|}{2} & 1.65 & 1.82 & 1.9 & 142.3 & 155 & 163.4 \\
\hline & \multicolumn{2}{|c|}{2.5} & 1.75 & 1.96 & 2.15 & 140.1 & 152 & 161.2 \\
\hline & \multicolumn{2}{|c|}{3} & 1.92 & 2.12 & 2.32 & 137 & 148.5 & 157 \\
\hline \multicolumn{3}{|c|}{ Mean values of derma Schell Speed } & 1.48 & 1.58 & 1.76 & 148.92 & 163 & 174.51 \\
\hline \multirow{3}{*}{\multicolumn{2}{|c|}{$\begin{array}{l}\text { Mean values of straw } \\
\text { moisture content }\end{array}$}} & 10.2 & 1.3 & 1.44 & 1.68 & 152.96 & 170.80 & 185.64 \\
\hline & & 13.2 & 1.5 & 1.6 & 1.74 & 151.18 & 163.64 & 174.5 \\
\hline & & 15 & 1.64 & 1.7 & 1.88 & 142.64 & 154.56 & 163.4 \\
\hline \multirow{5}{*}{\multicolumn{2}{|c|}{$\begin{array}{l}\text { Mean values of feeding } \\
\text { roller Speed }\end{array}$}} & 1 & 1.18 & 1.29 & 1.35 & 153.8 & 168.2 & 180.6 \\
\hline & & 1.5 & 1.36 & 1.48 & 1.55 & 151.7 & 165.43 & 177.33 \\
\hline & & 2 & 1.46 & 1.6 & 1.7 & 149.23 & 163.03 & 174.66 \\
\hline & & 2.5 & 1.59 & 1.78 & 1.88 & 146.83 & 160.83 & 171.9 \\
\hline & & 3 & 1.79 & 1.95 & 2.01 & 143.06 & 157.5 & 168.06 \\
\hline
\end{tabular}


The consumed energy increased by about $60 \%$ when the feeding roller speed increased from 1 to $3 \mathrm{~m} / \mathrm{s}$. However, the consumed energy increased by increasing the derma schell speed for all straw moisture contents and feeding roller speed. The consumed energy decreased by $20 \%$ when the derma schell speed decreased from 850 to 500 r.p.m at straw moisture content of $15 \%$ and feeding roller speed of $3 \mathrm{~m} / \mathrm{s}$. Generally, the minimum values of the consumed energy were recorded with straw moisture content of $10.2 \%$, feeding roller speed of $1.0 \mathrm{~m} / \mathrm{s}$ and derma schell speed of 500 r.p.m.

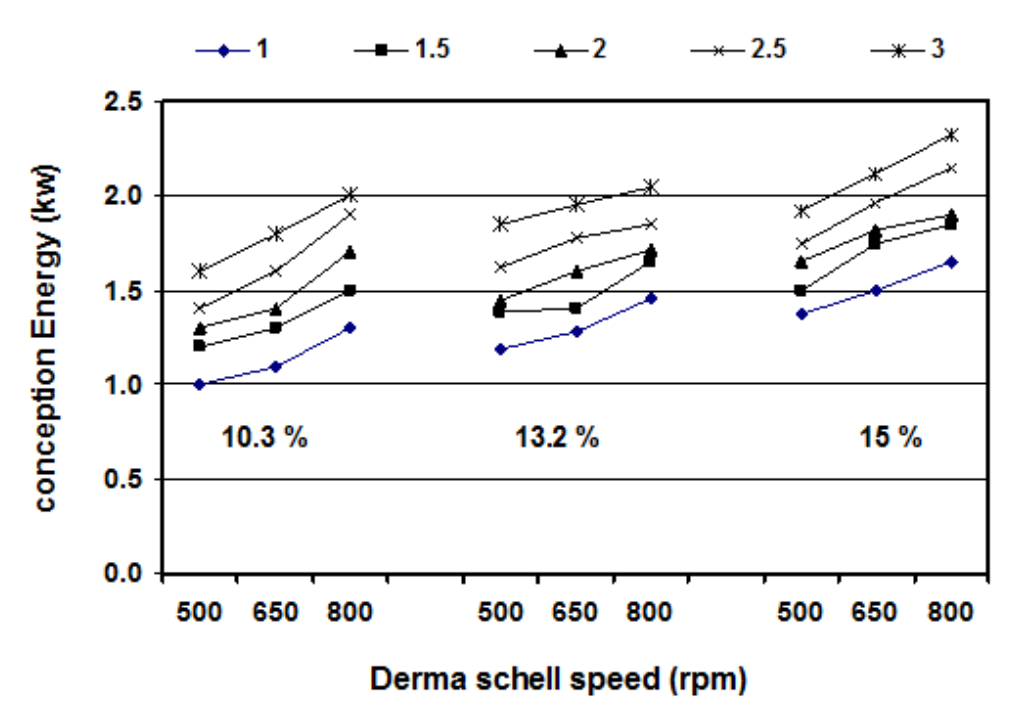

Fig.7: Effect of straw moisture content, feeding roller speed and derma schell speed on Consumed energy.

\section{4- Quality of fiber:}

\section{a- Fineness degree of fiber:}

There was a significant effect of straw moisture content, feeding roller speed and derma schell speed on the fiber fineness as shown in table 3 and fig 8 . It is evident that, the fiber fineness decreased by increasing the straw moisture content for all the feeding roller and derma schell speeds. The straw moisture content of $10.2 \%$ attained the maximum value of fiber fineness of $191.6 \mathrm{~mm} / \mathrm{mg}$ at feeding roller speed of $1 \mathrm{~m} / \mathrm{s}$ and derma schell speed of 800 r.p.m. These results may be due to increasing derma schell speed that facilitates the rotation derma schell in unit time through 
the flax stalk material. The feeding roller speeds of 1, 1.5, 2, 2.5 and 3 $\mathrm{m} / \mathrm{s}$ gave fiber fineness of 175.03, 172.30, 169.67, 167.37 and 164.63 $\mathrm{mm} / \mathrm{mg}$, respectively. It is clear that, increasing the feeding roller speed tended to decrease the fiber finenss for all the straw moisture contents and derma schell speeds. However, the feeding roller speed of $1 \mathrm{~m} / \mathrm{s}$ gave maximum value of fiber fineness. On the other hand, the derma schell speed of 800 r.p.m recorded the maximum value of fiber fineness of 191.6 $\%$ compared with the other speeds for straw moisture content $10.2 \%$ and feeding roller speed of $1 \mathrm{~m} / \mathrm{s}$. Finally, the results indicated that the maximum value of fiber fineness was obtained with straw moisture content of $10.2 \%$, feed roller speed of $1 \mathrm{~m} / \mathrm{s}$ and derma schell speed of 800 r.p.m.

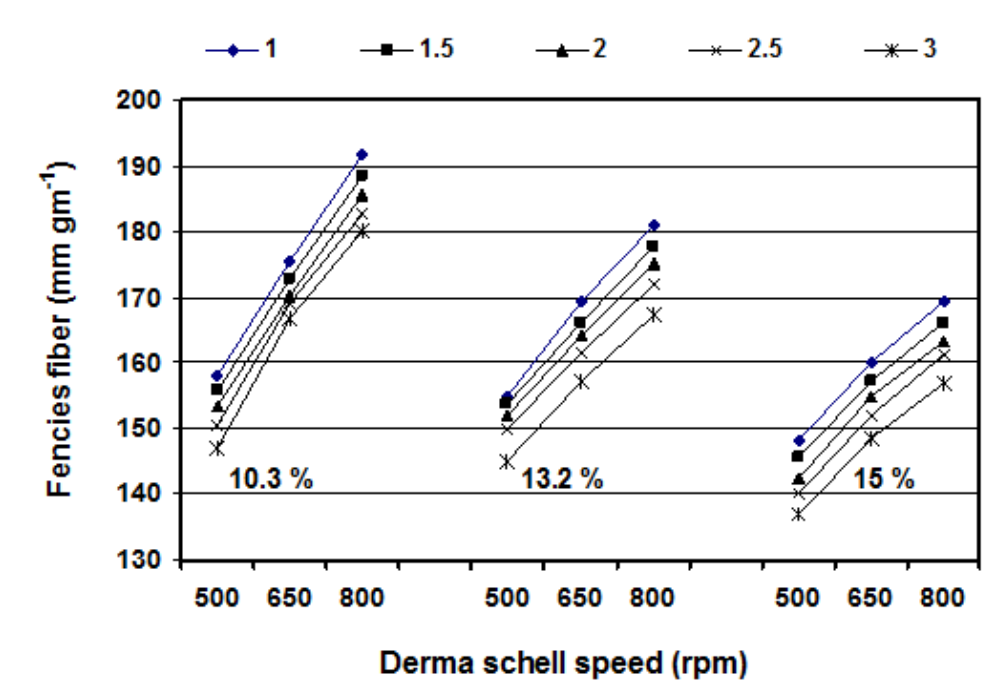

Fig.8: Effect of straw moisture content, feeding roller speed and derma schell speed on fineness fibre.

\section{b -length of fiber:}

The fiber length ranged from 61.3 to $92.8 \mathrm{~cm}$ at variation of straw moisture content from 10.2 to $15 \%$, feeding roller speed from 1 to $3 \mathrm{~m} / \mathrm{s}$ and derma schell from 500 to 800 r.p.m as shown in table 4 and fig 9 .The results indicated that increasing the straw moisture content tended to decrease the fiber length for all feeding roller and derma schell speeds.The fiber length decreased by $20 \%$ when the straw moisture content increased from 10.2 to $15 \%$. The data also demonstrated that the 
fiber length decreased by increasing the feeding roller speed for all the straw moisture contents and derma schell speeds. The feeding roller speed of $1.0 \mathrm{~m} / \mathrm{s}$ attained the maximum average value of fiber length $(90.1 \mathrm{~cm})$ at straw moisture content of $10.2 \%$. These results may be due to increasing material stalk flax opening in derma Schell in unit time. On the other hand, increasing the derma schell speed tended to decrease the fiber length for all straw moisture contents and feeding roller speeds. Generally, the maximum average value of fiber length $(92.8 \mathrm{~cm})$ was obtained with straw moisture content of $10.2 \%$, feeding roller speed of $1.0 \mathrm{~m} / \mathrm{s}$ and derma schell speed of 500 r.p.m

Table (4) Mean values length of fiber, tension force of fiber, Mpa for separation fiber flex at different moisture content, feeding roller speed and derma Schell Speed

\begin{tabular}{|c|c|c|c|c|c|c|c|c|}
\hline \multirow{3}{*}{$\begin{array}{l}\text { M. C } \\
, \%\end{array}$} & \multirow{3}{*}{\multicolumn{2}{|c|}{$\begin{array}{l}\text { feeding roller } \\
\text { Speed }, \mathrm{m} / \mathrm{sec}\end{array}$}} & \multicolumn{3}{|c|}{ length of fiber ,cm } & \multicolumn{3}{|c|}{ Tension force of fiber, Mpa } \\
\hline & & & \multicolumn{6}{|c|}{ Derma Schell Speed, r.p. m } \\
\hline & & & 500 & 650 & 800 & 500 & 650 & 800 \\
\hline \multirow{5}{*}{10.2} & \multicolumn{2}{|c|}{1} & 92.8 & 90.3 & 87.2 & 1280 & 1160 & 1020 \\
\hline & \multicolumn{2}{|c|}{1.5} & 92.1 & 88.2 & 86.5 & 1291 & 1172 & 1032 \\
\hline & \multicolumn{2}{|c|}{2} & 91.6 & 86.7 & 85 & 1305 & 1180 & 1041 \\
\hline & \multicolumn{2}{|c|}{2.5} & 91 & 84.2 & 83.2 & 1317 & 1191 & 1055 \\
\hline & \multicolumn{2}{|c|}{3} & 89.1 & 81.9 & 80 & 1326 & 1201 & 1076 \\
\hline \multirow{5}{*}{13.2} & \multicolumn{2}{|c|}{1} & 85.5 & 83.1 & 80 & 1650 & 1590 & 1510 \\
\hline & \multicolumn{2}{|c|}{1.5} & 83.1 & 82 & 79 & 1661 & 1595 & 1518 \\
\hline & \multicolumn{2}{|c|}{2} & 82 & 80.7 & 77.2 & 1675 & 1615 & 1531 \\
\hline & \multicolumn{2}{|c|}{2.5} & 80 & 78.3 & 75.6 & 1687 & 1627 & 1540 \\
\hline & \multicolumn{2}{|c|}{3} & 79 & 76.1 & 73.1 & 1696 & 1641 & 1562 \\
\hline \multirow{5}{*}{15} & \multicolumn{2}{|c|}{1} & 77.4 & 73.2 & 69.8 & 1952 & 1930 & 1882 \\
\hline & \multicolumn{2}{|c|}{1.5} & 75 & 71.8 & 66.7 & 1958 & 1934 & 1887 \\
\hline & \multicolumn{2}{|c|}{2} & 73.2 & 70.1 & 65.1 & 1965 & 1940 & 1893 \\
\hline & \multicolumn{2}{|c|}{2.5} & 70.8 & 68 & 63 & 1975 & 1944 & 1898 \\
\hline & \multicolumn{2}{|c|}{3} & 68.2 & 65.3 & 61.3 & 1987 & 1953 & 1892 \\
\hline \multicolumn{3}{|c|}{ Mean values of derma Schell Speed } & 82.05 & 78.66 & 75.51 & 1648.33 & 1578.2 & 1489.13 \\
\hline \multirow{3}{*}{\multicolumn{2}{|c|}{$\begin{array}{l}\text { Mean values of straw } \\
\text { moisture content }\end{array}$}} & 10.2 & 91.32 & 86.26 & 84.38 & 1303.8 & 1180.8 & 1044.8 \\
\hline & & 13.2 & 81.92 & 80.04 & 76.98 & 1673.8 & 1613.6 & 1532.2 \\
\hline & & 15 & 72.92 & 69.68 & 65.18 & 1967.4 & 1940.2 & 1890.4 \\
\hline \multirow{5}{*}{\multicolumn{2}{|c|}{$\begin{array}{l}\text { Mean values of feeding } \\
\text { roller Speed }\end{array}$}} & 1 & 85.23 & 82.2 & 79 & 1627.33 & 1560 & 1470.66 \\
\hline & & 1.5 & 83.4 & 80.66 & 77.4 & 1636.66 & 1567 & 1479 \\
\hline & & 2 & 82.26 & 79.16 & 75.76 & 1648.33 & 1578.3 & 1488 \\
\hline & & 2.5 & 80.6 & 76.83 & 73.93 & 1659.66 & 1587.33 & 1497.66 \\
\hline & & 3 & 78.76 & 74.43 & 71.46 & 1669.66 & 1598.33 & 1510 \\
\hline
\end{tabular}




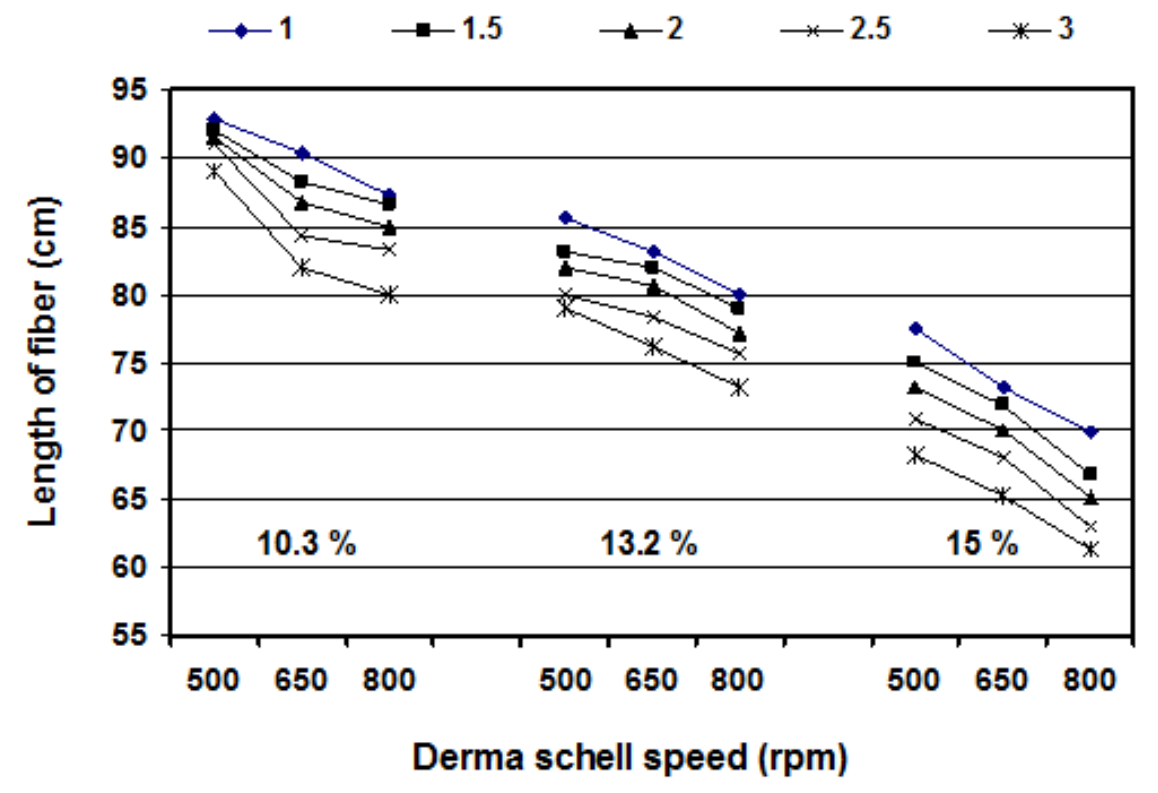

Fig.9: Effect of straw moisture content, feeding roller speed and derma schell speed on length of fiber.

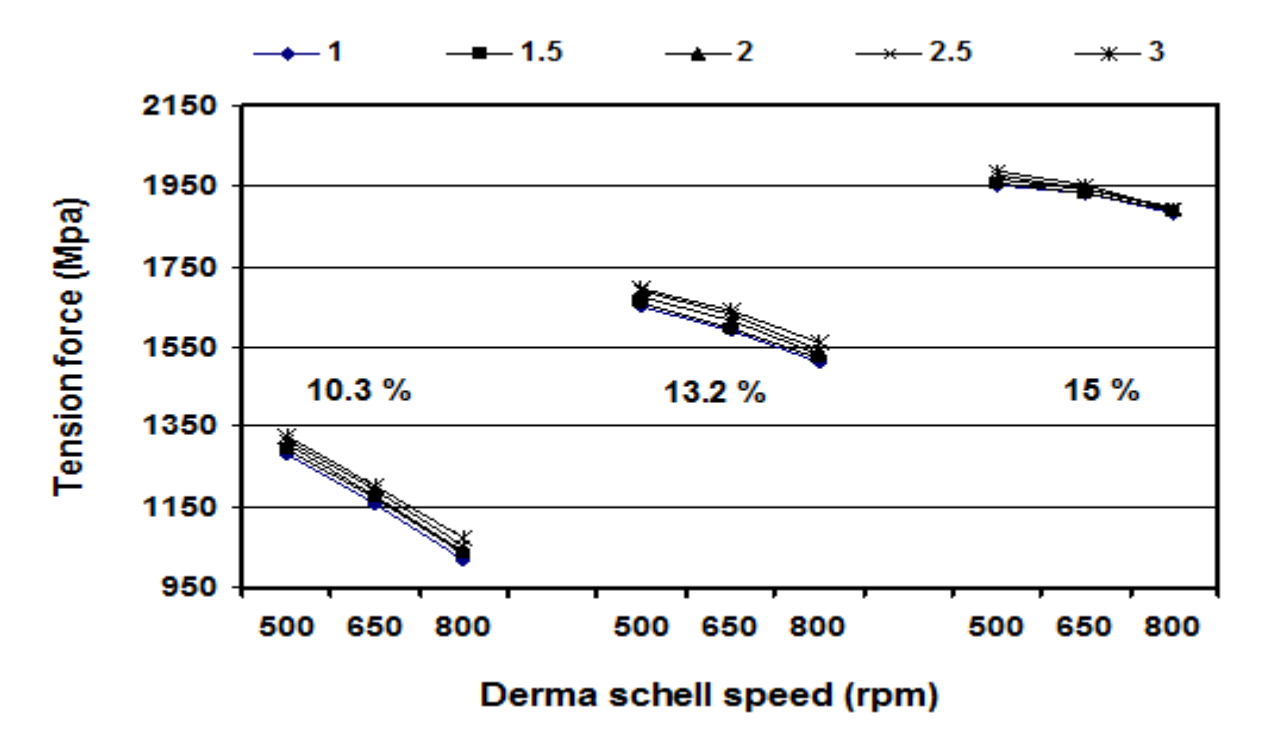

Fig.11: Effect of straw moisture content, feeding roller speed and derma schell speed on tension force of fiber. 


\section{c-Tension force of fiber:}

Tension force of fiber is considered an important parameter to evaluate the performance of separating machine. Table 4 and fig 11 show the effect of straw moisture content, feeding roller speed and derma schell speed on the tension force of fiber. Data indicated that the increase in straw moisture content from 10.2 to $15 \%$ tend to increase the tension force of fiber from 1176.5 to1932.7 Mpa . The maximum tension force of fiber was obtained with the straw moisture content of $15 \%$ for all feeding roller and derma schell speeds. The data also showed that the tension force of fiber increased by increasing the feeding roller speed from 1.0 to $3 \mathrm{~m} / \mathrm{s}$ for all the straw moisture contents and derma schell speeds. The feeding roller speed of $3 \mathrm{~m} / \mathrm{s}$ gave the maximum average value of tension force of fiber $1987 \mathrm{Mpa}$ at straw moisture content of $15 \%$ and derma schell speed of 500 r.p.m. On the other hand, the obtained average values of tension force of fiber were 1987, 1953 and 1892 Mpa at derma schell speeds of 500, 650 and 800 r.p.m with straw moisture content of $15 \%$ and feeding roller speed of $3 \mathrm{~m} / \mathrm{s}$. Generally, it is clear that the straw moister content of $15 \%$, feeding roller speed of $3 \mathrm{~m} / \mathrm{s}$ and derma schell speed of 500 r.p.m gave the maximum tension force of fiber $1987 \mathrm{Mpa}$ but, the minimum value of fiber tension force 1020 Mpa was recorded with the straw moisture content of $10.2 \%$, feeding roller speed of $1 \mathrm{~m} / \mathrm{s}$ and derma schell speed of 800 r.p.m. These results may be due to the increase of derma schell speed that facilitates the rotation derma schell in unit time through the stalk flax material Lead to Lack of fiber withstand tensile forces.

\section{CONCLUSION}

The present study concluded the main following points:

1. The manufactured separating machine had a good performance in separating and cleaning fiber flax where, the machine productivity reached $72.1 \mathrm{~kg} / \mathrm{h}$, separating efficiency $82.13 \%$. Whereas, the fiber fineness degree, tension force and length were $191.6 \mathrm{~mm} / \mathrm{mg}, 1987$ Mpa and $92.8 \mathrm{~cm}$, respectively.

2. The results showed that decreasing both straw moisture content and feeding roller speed tend to increase separating efficiency, fiber fineness and length for all the derma schell speeds. 
3. Results also, indicated that the increment in derma schell speed tend to increase the separating efficiency, consumed energy and fiber fineness while, machine productivity, fiber length and tension force decreased for all straw moisture contents and feeding roller speeds.

4. The data demonstrated that the straw moisture content of $10.2 \%$, feeding roller speed of $1 \mathrm{~m} / \mathrm{s}$ and derma schell speed of 800 r.p.m recorded the maximum values of separating efficiency of $82.13 \%$, fiber fineness of $191.6 \mathrm{~mm} / \mathrm{mg}$ and fiber length of $92.8 \mathrm{~cm}$.

5. The minimum value of the consumed energy for separating the flax stalks of $1 \mathrm{kw}$ was obtained with straw moisture content of $10.2 \%$, feeding roller speed of $1 \mathrm{~m} / \mathrm{s}$ and derma schell speed of 500 r.p.m.

6. It is recommended for the operators of the manufactured separating machine to operate it at straw moisture content of $10.2 \%$, feeding roller speed of $1 \mathrm{~m} / \mathrm{s}$ and derma schell speed of 800 r.p.m to obtain the optimum performance.

\section{REFERENCES}

Anthony, W.S. (2003). Device to separate contaminants from cotton and flax. Article · January 2003 with 20 Reads

Anthony, W.s. (2005). Development of machines to separate fiber and shave from seed flax straw. Applied Engineering in Agriculture. 21(6):1057-1063.

Anthony,W.S.(2002).Separation of fiber from seed flax straw. Applied Engineering in Agriculture 18(2):227-233.

Chancellor, W. J. 1981. Substituting information for energy in agricultural. Trans. ASAE Paper No. 0001- 2351.

Eichhom, S.I.et al. (2001) .Journal of Materials Science. Review Current international research into cellulosic fibres and composites. (36):2107-2131.

\section{Fouda,T.Z.,Badr,S.E.,Derbala,A.A.,andA.E.Elashry(2011).}

Manufacture and performance evaluation of a local machine for separating flax fibers. Annual Conference of the Misr Soc. Of Ag. Eng. 26-27 October 
Ismail(2009). The technological properties of flax fibers and the methods of estimating them, El-Felaha Jour. 46(5): 466-476. (In Arabic).

Lockwood,F.B.and R.Dunstan (1971). Electrical engineering principles. Heinemann Educational Books. Ltd. London.

Mohanty,A.K., M. Misra and L.T.Drzal. (2001). Surface modifications of natural fibers and performance of the resulting biocomposites: An overview. Composite Interfaces 8(5):313-343.

Molloy,R.M. (2000). A study of the plant, fiber and seed development in flax and linseed (linum usitatissimum) grown at a range of seed rates. Journal of Agricultural Science, (135): 361-369.

Oelke, E.S. Johnson, P. Ehrhardt, and V. Comstock, (1987). From flax straw to linen fiber. Agricultural fact sheet 3339.Minncsota Extension Service, University of Minncsota. St. Paul, Minn.

Radwan, B.R.H. and A. Momtaz(1966). The technological properties of flax fibers and the methods of estimating them, El-felaha Jour.46 (5):466-476.(in Arabic).

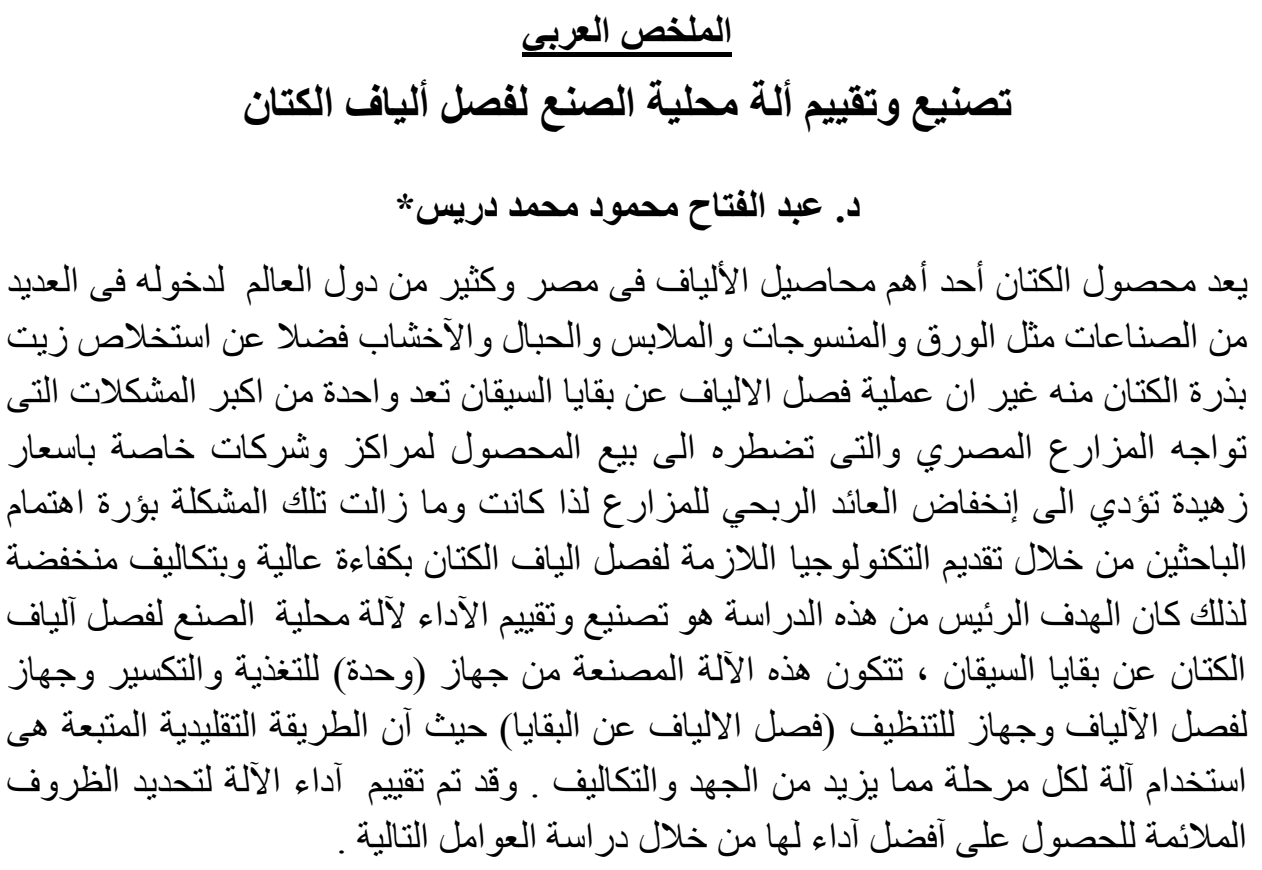

*استاذ الهندسة الزراعية المساعد ـ كلية الزراعة - جامعة الأزهر - أسيوط. 


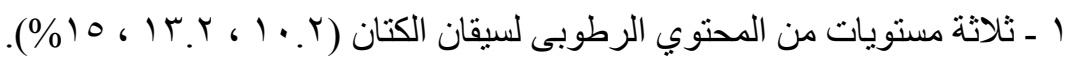

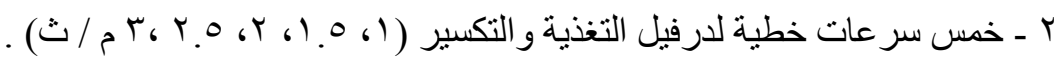

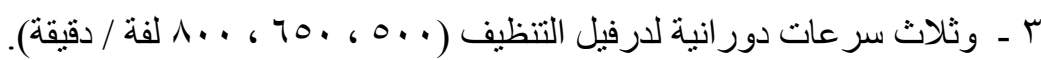
وقد تم دراسة نآثير العوامل السابقة على المتغيرات التالية. كفاءة الفصل لالياف الكتان- السعة الانتاجية للالة ـ الطاقة المستهلكة- جودة الالياف ( نعومة الاليافـ طول الاليافـ متانة الالياف).

\section{ويمكن تلخيص النتائج المتحصل عليها كمايلي:}

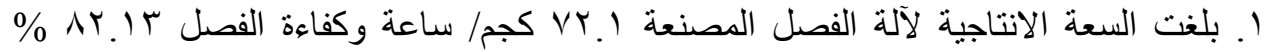

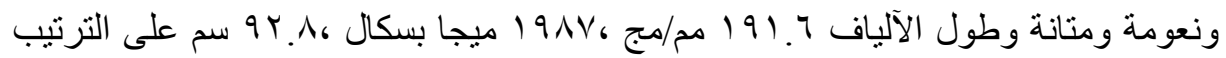

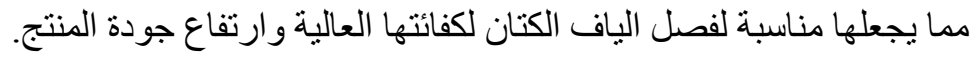
r. إرتفعت قيم كلا من كفاءة الفصل ونعومة وطول الآلياف بإنخفاض كل من المحتوى الرطوبي لسيقان الكتان و السر عة الخطية لدرفيل التغذية والتكسير.

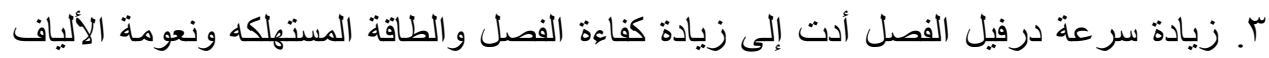
بينما قلت كل من طول ومتانة الألياف وانتاجية الآلة.

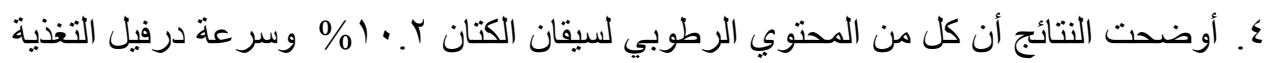

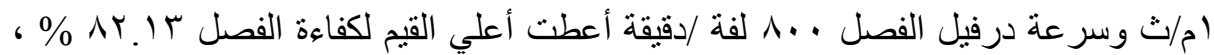

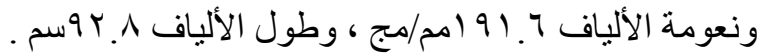

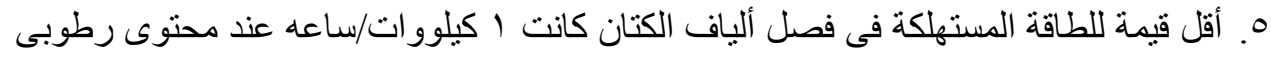

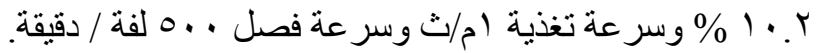

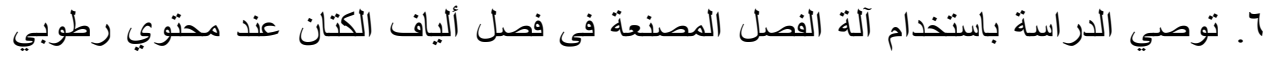

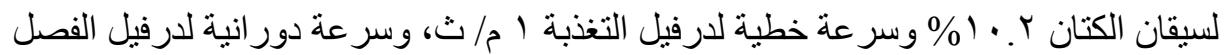

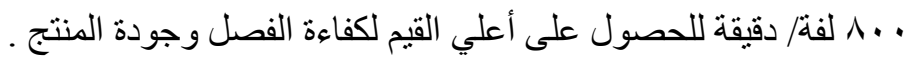

